\title{
Penerapan Pemberian Kompres Hangat Terhadap Penurunan Nyeri Menstruasi Pada Remaja Putri
}

\author{
Laili Mustaghfiroh ${ }^{1 *}$, Windha Widyastuti ${ }^{2}$ \\ 1,2 Program Studi Diploma Tiga Keperawatan, Universitas Muhammadiyah Pekajangan \\ Pekalongan, Indonesia \\ *email: lailly2332@gmail.com
}

\begin{abstract}
Menstrual pain is acommon problem experienced by many teenagers during menstruation. This pain can disturb them in doing their daily activities, thus it must be handled appropriately, for instance by applying warm compress. This scientific report aimed to find out whether warm compress therapy could reduce menstrual pain. This research was a case study where tow teenagers experiencing menstrual pain were treated as participants. A Numeric Rating Scale was used as an instrument to measure and gather the data. The intervention given to the participants was the application of warm compress for 10 minutes given once a day for two days. The result showed that before the intervention was given, the pain scale was 5 in case I and 4 in case II. After the intervention was given, the pain scale was 1 in case I and 0 in case II. Therefore, it can be concluded that warm compress could reduce menstrual pain experienced bt teenagers. Thus, health workers are expected to be able to apply and teach warm compress therapy to teenagers who experience menstrual pain.
\end{abstract}

Keywords: warm compresses, menstrual pain, adolescents

\begin{abstract}
Abstrak
Nyeri menstruasi adalah salah satu masalah ketidaknyamanan yang banyak dikeluhkan remaja saat menstruasi. Nyeri ini dapat menganggu kegiatan sehari-hari remaja salah satunya belajar, sehingga harus ditangani dengan tepat seperti halnya dengan tindakan kompres hangat. Karya tulis ilmiah ini bertujuan untuk mengetahui adanya penurunan nyeri setelah dilakukan terapi kompres hangat. Metode yang digunakan yaitu studi kasus pada dua remaja yang mengalami nyeri menstruasi. Instrumen penerapan berupa lembar observasi pengukuran nyeri menggunakan Numerice Rating Scale. Intervensi dengan menerapkan kompres hangat selama 10 menit diberikan sekali dalam sehari selama dua hari. Hasil menunjukkan sebelum penerapan, skala nyeri 5 pada kasus I dan 4 pada kasus II. Setelah dilakukan penerapan skala nyeri turun menjadi 1 pada kasus I dan 0 pada kasus II. Kesimpulannya adalah kompres hangat dapat menurunkan nyeri menstruasi yang dialami remaja. Saran bagi tenaga kesehatan, diharapkan dapat menerapkan maupun mengajarkan terapi kompres hangat pada remaja yang mengalami nyeri menstruasi.
\end{abstract}

Kata kunci: Kompres hangat; Nyeri Menstruasi; Remaja

\section{Pendahuluan}

Remaja adalah usia antara 10 sampai 19 tahun. Remaja akan mengalami pubertas, dimana seorang anak mengalami perubahan fisik, hormonal, dan seksual serta mampu melakukan reproduksi. Hal ini ditandai dengan mulainya remaja putri mengalami menstruasi [5]. Menstruasi adalah proses keluarnya darah dari dalam rahim yang banyak mengandung pembuluh darah dan sel telur yang tidak dibuahi. Menstruasi datang setiap bulan pada usia reproduksi, banyak wanita maupun remaja 


\section{Prosiding Seminar Nasional Kesehatan 2021 Lembaga Penelitian dan Pengabdian Masyarakat Universitas Muhammadiyah Pekajangan Pekalongan}

yang mengalami ketidaknyaman fisik saat menjelang atau selama menstruasi, salah satunya adalah nyeri menstruasi atau dismenore [10].

Nyeri menstruasi merupakan menstruasi yang disertai rasa sakit dan kram, kekakuan dibawah perut yang terjadi menjelang atau selama menstruasi [6]. Nyeri ini dapat disebabkan oleh kontraksi rahim dan beberapa faktor lainnya seperti faktor hormonal, kelainan organ, psikis dan konstitusi [13].

Angka kejadian dismenore di Indonesia sebesar 64,25\%, yang terdiri dari Dysmenorrhea primer sebersar 54,89\% dan Dysmenorrhea sekunder sebesar 9,36\%. Dismenore primer dialami oleh $60-75 \%$ remaja [13]. Berdasarkan data dari profil Dinas Kesehatan Provinsi Jawa Tengah pada tahun 2017, jumlah remaja usia 10-19 tahun sebesar 28,99\%, sedangakan yang menagalami Dysmenorrhea di provinsi jawa tengan mencapai $14,65 \%$ [6].

Nyeri menstruasi pada remaja putri dapat menimbulkan gangguan aktifitas fisik, akibat lebih lanjut dari nyeri ini yaitu menurunnnya konsenterasi sehingga dapat mengganggu proses kegiatan belajar [13]. Oleh karena itu nyeri menstruasi pada remaja harus ditangani dengan tepat untuk menghindari dampak negatif yang akan muncul [10]. Nyeri menstruasi dapat ditangani dengan banyak cara, salah satunya dengan kompres hangat [8].

Kompres hangat merupakan terapi nonfarmakologi yang dapat dilakukan secara mandiri [13]. Efek hangat dari kompres dapat menyebabkan vasodilatasi pada pembuluh darah yang nantinya akan meningkatkan aliran darah ke jaringan penyaluran zat asam dan makanan ke sel-sel diperbesar dan pembuangan zat-zat di perbaiki hal tersebut akan mengurangi rasa nyeri haid yang disebabkan suplai darah ke endometrium kurang [22].

Ada beberapa penelitian terkait dengan masalah ini diantaranya penelitian yang pernah dilakukan oleh Pangesti, Lestari dan Riyanto pada tahun 2017 tentang Pengurangan nyeri dismenore primer pada remaja putri dengan kompres hangat, yang menyatakan bahwa ada pengaruh kompres hangat, terhadap penurunan nyeri Dysmenorrhea primer dengan $P=0,000(P<0,05)$. Hal ini diperkuat dengan penelitian yang dilakukan oleh Maidartati, Hayati, Hasanah pada tahun 2018 tentang Efektifitas terapi kompres hangat terhadap penurunan nyeri bismenore pada remaja di Bandung, yang menunjukkan adanya efektivitas pemberian kompres hangat penurunan nyeri haid pada remaja usia 13-15 Kota Bandung dengan $P=0,000(P<0,05)$.

Berdasarkan survey pendahuluan di Kelurahan Kalibaros Kota Pekalongan. Melalui wawancara yang dilakukan pada 10 remaja putri terdapat 7 remaja mengalami nyeri menstruasi, untuk penanganannya tiga remaja mengkonsumsi obat pengurang nyeri dan empat remaja lainya mengatasinya dengan beristirahat. Penanganan nyeri menstruasi dengan menggunakan kompres hangat tidak pernah dilakukan oleh sepuluh remaja tersebut. Permasalahan tersebut menarik perhatian penulis untuk menyusun karya tulis ilmiah dengan judul "pengaruh pemberian kompres hangat terhadap penurunan nyeri menstruasi pada remaja putri". 


\section{Prosiding Seminar Nasional Kesehatan $\mathbf{2 0 2 1}$ Lembaga Penelitian dan Pengabdian Masyarakat Universitas Muhammadiyah Pekajangan Pekalongan}

\section{Literature Review}

Menstruasi adalah proses keluarnya darah dari dalam rahim yang banyak mengandung pembuluh darah dan sel telur yang tidak dibuahi. Menstruasi datang setiap bulan pada usia reproduksi, banyak remaja yang mengalami ketidaknyaman fisik saat menjelang atau selama menstruasi, salah satunya adalah nyeri menstruasi atau dismenorea. Nyeri ini dapat disebabkan oleh kontraksi rahim dan beberapa faktor penyebab lainnya seperti faktor hormonal (ketidakseimbangan estrogen dan progesteron), faktor kelainan organ, faktor psikis, dan faktor konstitusi.

Nyeri menstruasi dapat menganggu kegiatan sehari-hari remaja salah satunya belajar, sehingga harus ditangani dengan tepat seperti halnya dengan tindakan kompres hangat. Kompres hangat adalah memberikan rasa hangat pada daerah tertentu dengan menggunakan cairan atau alat yang menimbulkan hangat pada bagian tubuh yang memerlukan. Hangat dari kompres dapat menyebabkan vasodilatasi pada pembuluh darah yang nantinya akan meningkatkan aliran darah ke jaringan penyaluran zat asam dan makanan ke sel-sel di perbesar dan pembuangan zat-zat di perbaiki yang dapat mengurangi rasa nyeri haid yang disebabkan suplai darah ke endometrium kurang.

\section{Metode}

Desain karya tulis ilmiah ini menggunakan desain studi kasus. Subyek studi kasus dalam karya tulis ilmiah ini adalah dua remaja usia 10-19 tahun yang mengalami nyeri menstruasi. Kriteria inklusi dari studi kasus ini adalah tidak memiliki riwayat penyakit kandungan, mengalami nyeri menstruasi, nyeri ringan hingga berat, bersedia menjadi subjek studi kasus, siklus menstruasi teratur. Kriteria eksklusi yaitu usia lebih dari 25 tahun, nyeri tidak tertahankan, tidak bersedia menjadi subjek studi kasus, mengalami siklus menstruasi tidak teratur. Nyeri menstruasi diukur menggunakan skala penilaian numeric (Numerical Rating Scale, NRS) yang diukur sebelum dan sesudah dilakukan kompres hangat. Kompres hangat pada perut bagian bawah yang terasa nyeri dengan menggunakan buli-buli atau kantong karet yang berisi air hangat bersuhu $40-45^{\circ} \mathrm{C}$ (diukur menggunakan termometer air), yang dibalut dengan kain. Kompres hangat dilakukan selama 10 menit (dilakukan penggantian air hangat dengan suhu awal 40$45^{\circ} \mathrm{C}$ setiap 5 menit sekali untuk mempertahankan suhu yang optimal), kompres diberikan $1 x$ perhari, selama 2 hari.

\section{Hasil dan Pembahasan}

\section{Hasil}

Tabel 4.1 Data responden sebelum dan sesudah dilakukan tindakan

\begin{tabular}{ccccc}
\hline & \multicolumn{4}{c}{ Karakteristik } \\
\cline { 2 - 5 } & Usia & Menarche & $\begin{array}{c}\text { Skala nyeri } \\
\text { Sebelum }\end{array}$ & $\begin{array}{c}\text { Skala nyeri } \\
\text { Sesudah }\end{array}$ \\
\hline Kasus I & 15 tahun & 13 tahun & 5 & 1 \\
Kasus II & 15 tahun & 13 tahun & 4 & 0 \\
\hline
\end{tabular}




\section{Prosiding Seminar Nasional Kesehatan Lembaga Penelitian dan Pengabdian Masyarakat Universitas Muhammadiyah Pekajangan Pekalongan}

Berdasarkan tabel diatas setelah kedua klien diberikan terapi kompres hangat selama dua hari menunjukkan adanya penurunan skala nyeri, masing-masing klien mengalami penurunan 4 skala nyeri, untuk klien kasus I dari skala 5 (nyeri sedang) menjadi skala 1 (nyeri ringan) sedangkan untuk klien kasus II dari skala 4 (nyeri sedang) menjadi skala 0 (tidak nyeri).

\section{Pembahasan}

Implementasi yang penulis lakukan pada kedua kasus ini sesuai dengan intervensi keperawatan yang telah disusun yaitu menerapkan terapi kompres hangat. Efek hangat dari kompres dapat menyebabkan vasodilatasi pada pembuluh darah yang nantinya akan meningkatkan aliran darah ke jaringan penyaluran zat asam dan makanan ke sel-sel di perbesar dan pembuangan zat-zat di perbaiki yang dapat mengurangi rasa nyeri haid yang disebabkan suplai darah ke endometrium kurang [22].

Penerapan terapi kompres hangat dilakukan selama dua hari dengan lama pemberian kompres 10 menit dengan suhu air $40^{\circ} \mathrm{C}-45^{\circ} \mathrm{C}$ (ganti air hangat dengan suhu awal yaitu $40^{\circ} \mathrm{C}-45^{\circ} \mathrm{C}$ setiap 5 menit sekali untuk mempertahankan suhu yang optimal) dengan pengukuran skala nyeri setiap sebelum dan sesudah dilakukan terapi menggunakan skala Numeric. Hal ini sama dengan penelitian yang dilakukan Maidartati, Hayati dan Hasanah dengan judul efektivitas terapi kompres hangat terhadap penurunan nyeri dismenore pada remaja di Bandung pada 23 kasus pada tahun 2018, bahwa kompres hangat dilakukan selama 10 menit, dengan suhu air $40^{\circ} \mathrm{C}-45^{\circ} \mathrm{C}$ serta pengukuran skala nyeri dilakukan sebelum dan sesudah diberikan tidakan kompres untuk dapat membandingkan apakan ada penurunan atau tidak menggunakan skala numerical rating scale (NRS).

Implementasi pada kedua kasus dilakukan selama dua hari pada hari pertama dan kedua menstruasi, selama pelaksanaan tindakan tidak terdapat kendala yang bermakna yang menghambat pelaksanaan terapi kompres hangat pada kedua kasus. Implementasi pada hari pertama diketahui adanya penurunan skala nyeri untuk klien kasus I dari skala 5 menjadi 3 sedangkan pada klien kasus II dari skala 4 menjadi skala 2. Implementasi pada hari kedua diketahui terdapat adanya penurunan skala nyeri untuk klien kasus I dari skala 3 menjadi skala 1 dan untuk klien kasus II dari skala 4 menjadi skala 0 , dari hasil tersebut menunjukkan adanya efektivitas kompres hangat terhadap penurunan nyeri.

Efektivitas kompres hangat terhadap penurunan nyeri telah dilakukan oleh beberapa penelitian sebelumnya, penelitian yang dilakukan Pangesti, Lestari dan Riyanto pada tahun 2018 dalam penelitian berjudul pengurangan nyeri dismenore primer pada remaja putri dengan kompres hangat, dan penelitian yang dilakukan Murtiningsih dan Karlina pada tahun 2015 dalam penelitian berjudul penurunan nyeri dismenorea primer melalui kompres hangat pada remaja dari kedua penelitian menunjukan hasil yang sama yaitu terdapat penurunan skala nyeri setelah dilakukan kompres hangat untuk pertama kalinya. Hal ini didukung hasil penelitian dari Diana, Mindarsih, dan Marlinawati pada tahun 2018 yang juga menunjukkan adanya pengaruh kompres hangat terhadap penurunan nyeri Dysmenorrhea pada remaja. 


\section{Prosiding Seminar Nasional Kesehatan 2021 Lembaga Penelitian dan Pengabdian Masyarakat Universitas Muhammadiyah Pekajangan Pekalongan}

\section{Kesimpulan}

Kesimpulan yang diperoleh dari penerapan kompres hangat terhadap penurunan nyeri menstruasi pada remaja putri didapatkan hasil adanya penurunan nyeri menstruasi pada kedua kasus. Saran bagi penulis berikutnya, diharpkan penulis berikutnya dapat terus mengembangkan dan memodifikasi kompres hangat dengan terapi lainnya untuk membantu mengurangi nyeri saat menstruasi.

\section{Referensi}

[1] Aspiani, "Buku Ajar Asuhan Keperawatan Maternitas Aplikasi NANDA, NIC dan NOC" Jakarta: CV. Trans Info Media, 2017.

[2] Diana, E. Mindarsih, \& V. Utari Marlinawati, "Pengaruh Kompres Air Hangat Terhadap Intensitas Nyeri Dysmenorrea Pada Remaja Didusun Randusari Desa Argomulyo Cangkiringan Sleman Yogyakarta" Jurnal medika respati, vol. 13, no.1, pp. 1907-3887, 2018.

[3] Fatmawati, "Diktat Keperawatan Maternitas I Menstruasi" Gresik: Program Studi ilmu keperawatan fakultas ilmu kesehatan universitas gersik, 2019

[4] Geri D. Hawitt, and Karen R. Gerancher, "Dysmenorrhea and Endometriosis in the Adolescent" American College Obstetricians and Gynecologist (ACOG), vol. 132, no. 6, 2018.

[5] Haryono Rudi, "Siap Menghadapi Menstruasi \& Menopouse" Yogyakarta: Gosyen, 2016.

[6] N. Husna, "Gambaran aktivitas olahraga pada penderita Dysmenorrhea di pondok pesantren al-mas'udiyyah putri 2 blater kabupaten semarang tahun 2019" 2019.

[7] B. Janiwarty, and H. Z. Piter, "Pendidikan Psikologi untuk Bidan Satuan Teori dan Terapannya" Yogyakarta: Andi Offset, 2013.

[8] H. Mahua, S. Mudayatiningsih, dan P. Perwiraningtyas, "Pengaruh Pemberian Kompres Air Hangat Terhadap Dismenore Pada Remaja Putri Di SMK Penerbangan Angkasa Singosari Malang" Nursing News, vol. 3, no. 1, 2018.

[9] Maidartati, S. Hayati, \& A. Permata Hasanah, "Evektifitas Terapi Kompres Hangat Terhadap Penurunan Nyeri Dismenore Ada Remaja Di Bandung" Jurnal Keperawatan BSI, vol. 6, no. 2, 2018.

[10] Murtiningsih \& Karlina Lina, "Penurunan nyeri Dysmenorrhea primer melalui kompres hangat pada remaja" vol. 3, no. 2, 2015.

[11] T. Nugroho, \& B. Utama, "Masalah Kesehatan Reproduksi Wanita" Yogyakarta: Nuha Medika, 2017.

[12] Nursalam, "Metodologi Penelitian IImu Keperawatan" Jakarta: Salemba Emban Patria, 2017.

[13] R. Hayu Pangesti, G. Indah Lestari, \& Riyanto, "Pengaruh Nyeri Dismenore Primer Pada Remaja Putri Dengan Kompres Hangat" Jurnal Kesehatan Metro Sai Wawai, vol. 10, no. 2, 2017. pp. 97-102.

[14] D. C. Rahayuningrum, "Perbedaan Pengaruh Teknik Relaksasi Nafas Dalam Dan Kompres Hangat Dalam Menurunkan Dismenore Pada Remaja SMA Negeri 3 Padang" Jurnal Medika Santika, vol. 7, no. 2, 2016. Pp. 2540-9611. 


\section{Prosiding Seminar Nasional Kesehatan 2021 Lembaga Penelitian dan Pengabdian Masyarakat Universitas Muhammadiyah Pekajangan Pekalongan}

[15] A. Ratnawati, "Asuhan Keperawatan Maternitas" Yogyakarta: Pustaka Baru Press, 2017.

[16] M. Shadine, "Penyakit Wanita Pencegahan, Deteksi Dini, Pengobatan" Yogyakarta: Citra Pustaka Yogyakarta, 2012.

[17] E. Sinaga, N. Saribanon, Suprihatin, N. Sa'adah, U. Salamah, Y. A. Murti, A. Trisnamiati, S. Lorita, "Manajemen Kesehatan Menstruasi" Jakarta: Global One, 2017.

[18] Tim ASASKI, "Buku Panduan Praktikum 18 Kompetensi Asisten Keperawatan" Jakarta: In Media, 2014.

[19] Tim Pokja SDKI DPP PPNI, "Standar Diagnosa Keperawatan Indonesia" Jakarta: DPP PPNI, 2017.

[20] Tim Pokja SIKI DPP PPNI, "Standar Intervensi Keperawatan Indonesia" Jakarta: DPP PPNI, 2018.

[21] S. H. Wahyuni, "Aplikasi Kompres Hangat Untuk Mengatasi Nyeri Akut Pada Remaja Dengan Dismenore" 2018

[22] R. S. Wati, "Pengaruh Pemberian Kompres Hangat Terhadap Penurunan Nyeri Menstruasi (Dismenore) Pada Remaja Putri Siswi Kelas VII SMPN 3 Kecamatan Maospati Kabupaten Magetan" 2017

[23] E. Wenda, S. Mahanani, "Gambaran Gejala Menstruasi Pada Remaja Putri" Jurnal Stikes RSBK, vol. 11, no. 1, 2018. Pp. 2085-0921. 